\title{
Factors relating to energy conservation during sleep in mammals
}

\author{
J. A. HORNE \\ Department of Human Sciences, Loughborough University \\ Loughborough, Leicestershire, LE11 3TU, England
}

\begin{abstract}
It is proposed that sleep may serve a prime role as an energy conserver and immobilizer in the smaller and more primitive mammals, with REM sleep being particularly oriented to this purpose. However, with the evolution of the cortex and increasing body size, sleep may have become more directed towards the brain. While the earlier form of sleep may have been essentially REM sleep, this latter development of sleep may have been within non-REM sleep.
\end{abstract}

A recent review of mammalian sleep by Zepelin and Rechtschaffen (1974) correlated various sleep parameters with such constitutional factors as metabolic rate (MR), life span, and brain weight. The main conclusion was that total sleep time (TST) correlated more highly $(0.64)$ with MR than with any of the other constitutional factors. The authors considered that, as this correlation was so high, sleep might play a key role in energy conservation, whereby the enforced immobility of sleep facilitates energy conservation. Similar hypotheses have also been proposed by Berger (1975) and Snyder (1966), and have received much support among sleep researchers.

Although this correlation is significant, MR accounts for only a minority $(41 \%)$ of the variance of TST, and there are obviously other factors affecting TST. For example, Allison and Cicchetti (1976) provide statistical grounds for the safety of the sleeping organism also having a significant influence over sleep, particularly with REM sleep duration. The purpose of the present discussion is to examine the putative relationship between MR and energy conservation from three viewpoints-first, to point out that this hypothesis needs to be reconciled with the claims of thermoregulatory impairment and of possible inefficiencies in energy conservation during REM sleep; secondly, that it would appear that the degree of possible energy conservation during sleep is inversely related to body size; and thirdly, that cortical development and an animal's propensity towards relaxed wakefulness may also influence the energy conservation role for sleep.

\section{REM AND THERMOREGULATION}

The main organ for heat dissipation in the rabbit is the ear, which is richly supplied with capillaries.

I should like to thank Miss H. Dallosso and Dr. N. G. Norgan of this department, for their helpful comments during the writing of this paper.
Baker and Hayward (1967) find that REM sleep, unlike non-REM sleep, is always accompanied by an almost maximum constriction of these capillaries, resulting in an increase in body temperature. Even a high environmental temperature cannot reverse this effect. The cat and many hoofed mammals utilize as their main heat dissipating organ a carotid rete located in the cavernous sinus of the nose. Here, arterial blood is cooled, via a countercurrent system, by the latent heat of evaporation from the nasal mucosa. It has been reported by Baker and Hayward (1968) for sheep, and by Hayward and Baker (1969) and Baker (1972) for the cat, that during non-REM sleep there is a significant temperature drop across the rete, but in REM sleep no such drop is found. The drying up of nasal secretions in the cow (Toutain \& Ruckebusch, 1972) and the suppression of panting in the cat (Parmeggiani, Rabini, \& Cattalani, 1969; Parmeggiani \& Sabbatini, 1972) during REM sleep are doubtless related to the reduction of rete heat loss. The horns of even-toed ungulates are richly vasculated and act as a heat dissipator additional to the rete. In REM sleep, blood flow to the horns is reduced (Taylor, 1966). Man utilizes sweating as a prime mechanism for heat dissipation, and in REM sleep, unlike other sleep stages, sweating is lowered substantially (Henane, Buguet, Roussel, \& Bittel, 1977; Shapiro, Moore, Mitchell, \& Yodaiken, 1974).

It would seem that although these interspecies thermoregulatory responses of REM sleep appear to have a common factor of peripheral vasoconstriction, the cat, for example, displays no such constriction in peripheral capillaries during REM sleep (Parmeggiani, Zamboni, Cianci, \& Calasso, 1977; Reis, Moorhead, $\&$ Wooten, 1969). Such a response in a fur-clad mammal would be of minor thermoregulatory importance compared with the rete mechanisms. Therefore, it would appear that the thermoregulatory effects of REM sleep are not just a reflection of general peripheral vasoconstriction, but of a vasoconstriction in those organs responsible for heat dissipation. 
The relative propensities for acute thermogenesis in REM sleep and non-REM sleep have received little attention. In studies of the cat, Parmeggiani et al. (1969) and Parmeggiani and Sabbatini (1972) found that shivering thermogenesis is repressed in REM sleep but not in non-REM sleep. In the kangaroo rat, metabolic heat production can be increased by hypothalamic cooling in both wakefulness and nonREM sleep, but not in REM sleep (Glotzbach \& Heller, 1976). Nevertheless, it is unlikely that a mammal would seriously overheat, or even overcool, during REM sleep, as this state of sleep is "fragile" (Hartmann, 1973), and under such adverse environmental circumstances awakenings from REM sleep have been reported by Parmeggiani et al. (1969), Parmeggiani and Sabbatini (1972), and Shapiro et al. (1974).

In most of the studies of thermoregulatory events during sleep, the respective authors consider that thermoregulation as a whole fails or is seriously impaired during REM sleep. However, it would seem strange that normally homeothermic mammals should temporarily lose the ability to thermoregulate. This would imply that in a cool environment valuable energy in the form of heat might be wasted through ineffective heat conservation, especially as shivering thermogenesis during REM sleep has been shown to be impaired (Glotzbach \& Heller, 1976; Parmeggiani et al., 1969; Parmeggiani \& Sabbatini, 1972). Such a heat loss would run counter to the proposed energy conservation roles for sleep. If REM sleep does represent a failure of thermoregulation, then it might be expected that very small mammals sleeping in their own naturally cold environments would have little REM sleep. However, this is apparently not so. For example, from the data of Zepelin and Rechtschaffen (1974), the European hedgehog has about $3.9 \mathrm{~h}$ of daily REM sleep, the water opossum $6.6 \mathrm{~h}$, and the ground squirrel $3.4 \mathrm{~h}$.

From recent reviews of mammalian sleep by Allison and Cicchetti (1976), Meddis (1975), and Zepelin and Rechtschaffen (1974), it appears that REM sleep is one of the earliest of the recognizable sleep stages to evolve, and is quite evident in primitive adult mammals. REM sleep also seems to be the sleep stage that is probably the earliest to develop ontogenetically, as shown by Jouvet-Mounier, Astic, and Lacote (1970). These investigators have described welldeveloped REM sleep in the neonates of several mammalian species studied. In the human neonate, Anders, Emde, and Parmelee (1971), Dittrichova (1969), and Ellingson (1975) for example, describe how evident REM sleep is, and how it appears to become superseded by non-REM sleep states. Finally, the primitiveness of REM sleep is demonstrated by its apparent presence in the decerebrate cat (Jouvet, Pellin, \& Mounier, 1961), although non-REM sleep is not so evident.
It would seem that from the various reports described, the thermoregulatory responses during REM sleep appear to be almost wholly associated with the prevention of heat loss, that is, energy conservation, rather than with acute thermogenesis. As REM sleep seems to be both phylogenetically and ontogenetically an early form of sleep, it is possible that the physiological concomitants of REM sleep may be of a more basic nature, a factor which may account for the particular thermoregulatory qualities of REM sleep. Hence, the thermoregulatory emphasis of REM sleep may be on one of the earliest thermoregulatory responses to evolve, namely, heat conservation. Although it is not exactly clear how homeothermy evolved, from the evidence of ontogeny, Hensel (1973), in his review of thermoregulation, states that the initial emphasis is upon the prevention of heat loss and, to a lesser extent, acute thermogenesis by the metabolism of brown adipose tissue (BAT). Fox and Edholm (1963) and Hensel (1973) describe in the human neonate a well-developed coldinduced peripheral vasoconstrictor response. On the other hand, it is well known that the human neonate is unable to shiver (Smith, 1959). BAT thermogenesis is, however, quite apparent in the neonate, but soon declines with the normal disappearance of the tissue during infancy. The neonate also has a very poor response to a hot environment, particularly as sweating is not possible (Smith, 1959; Foster, 1976).

Thus, rather than mammalian sleep in its entirety being a conserver of energy and perhaps an immobilizer, as often proposed, it may well be the apparently earlier REM sleep which is specifically oriented to these purposes. As BAT only occurs in coldacclimatized adult mammals, and as BAT thermogenesis appears to be, at least ontogenetically, an early form of thermogenesis, it would be interesting to see if this nonshivering thermogenesis is present in cold-adapted adult mammals during REM sleep. No such studies have yet been performed.

There appear to have been three studies which have investigated heat loss in mammals during sleep (Henane et al., 1977; Shapiro et al., 1974; Toutain \& Webster, 1975). The most detailed was by Henane et al. (1977), using human subjects. Here, total body evaporation, core temperature, and skin temperature were measured in three subjects over several nights, under ambient and warm environmental conditions. Under both conditions, sweat loss dropped markedly during REM sleep, as compared with non-REM sleep. Accordingly, as evaporative heat loss declined, skin temperature rose to the environmental temperature. This, in turn, was followed by a rise in rectal temperature, with a phase lag due to thermal inertia. Similar reductions in sweat rate during REM sleep were also reported by Shapiro et al. (1974). It would seem, therefore, that these findings would support an energy conservation role for REM sleep. 
Toutain and Webster's (1975) study of cows and sheep measured $\mathrm{O}_{2}$ consumption (indirect calorimetry) and body heat loss by direct calorimetry during wakefulness and sleep. Unfortunately, these animals have short REM periods. This factor, coupled with a thermal inertia, whereby any thermoregulatory changes caused during REM sleep would spill over into non-REM sleep, and vice versa, made analysis of the data difficult. However, it would seem, from their data, that while $\mathrm{O}_{2}$ consumption showed little change from REM to non-REM sleep in both species, in the cow, heat loss was lower in REM sleep compared with waking and non-REM sleep levels. In the sheep, REM and non-REM sleep levels of heat loss were similar, but both were lower than for waking levels. The authors pointed out that the shorter REM sleep periods of the sheep compared with the cow made the differentiation of heat loss levels between REM and non-REM sleep particularly difficult with the former animal. As no data on core temperatures appear to have been collected in this study, no firm conclusions can be drawn about the energy conservation status of REM sleep. Nevertheless, the data from the cow would seem to support the present proposals.

Although the commonly accepted phenomenon of a reduced muscle tone during REM sleep might also support energy conservation and, perhaps, immobilization roles for REM sleep, it would seem that this phenomenon is really evident only in the head and neck muscles (Jacobson, Kales, Lehmann, \& Hoedemaker, 1964). However, this atonia may support a hypothesis that REM sleep is a primitive sleep state, as the facial and neck muscles may well represent the branchiomeric system of striated muscles, with their unique form of innervation, found in primitive animals. According to Romer (1962), this system is still prominent in the head and neck of all advanced mammals.

In concluding this thermoregulatory perspective of REM sleep, it must be remembered that not all other functions of REM sleep, whatever they may be, might also be of a phylogenetically early nature. REM sleep may well have evolved newer and more advanced functions, which may also be reflected in ontogeny.

\section{BODY SIZE AND ENERGY CONSERVATION}

Although REM sleep may be oriented particularly towards energy conservation, non-REM sleep may also appear to facilitate energy conservation through keeping the organism immobile. However, the benefits of energy conservation during sleep, or during any other form of immobility, increases with decreasing body size. It is well known that the larger the mammal, the lower is its resting MR per kilogram of body tissue, and it also would seem from available evidence (World Health Organisation, Note 1) that for most mammals, regardless of body size, the energy requirement for maintenance is about $30 \%-50 \%$ higher than for basal requirements. Thus, the net difference (gross - resting) in energy cost $(\mathrm{kcal} / \mathrm{kg}$ ) between a standard level of activity and rest will be greater with decreasing body size. For example, increases in running speeds elicit greater net increases in energy expenditure with the smaller mammal (SchmidtNielsen, 1972; Taylor, Schmidt-Nielsen, \& Raab, 1970; Tucker, 1970).

Within the sleep context, prevention of needless activity would yield substantial net energy savings per kilogram for small mammals but would yield smaller savings for larger mammals. Furthermore, in ecological terms and expressed as food eaten per kilogram of body weight, a small mammal can conserve more of an environment's food resources by being inactive than can a larger mammal.

\section{RELAXED WAKEFULNESS AND CORTICAL DEVELOPMENT}

Two questions now arise: first, whether mammals have to sleep in order to attain prolonged immobility and energy conservation, and second, whether the immobility of sleep saves significantly more energy than does relaxed wakefulness to warrant the evolution of sleep?

To begin with the first question, it is quite obvious that man and many larger mammals can enjoy long periods of relaxed, but not drowsy, wakefulness. However, small mammals appear not to be so disposed. Obviously, it is very difficult to observe a small mammal over $24 \mathrm{~h}$, in its natural environment, in order to determine if it is able to cease activity for any significant period without its becoming drowsy or sleeping. Although, from the few studies of rodents, by, for example, Garma and Verley (1969) and Gramsbergen, Schwartze, and Pretchl (1970), it would seem that such animals spend their lives either in active wakefulness (which includes grooming and infant rearing) or in sleep. Indeed, for them, sleep may be an enforced immobilizer.

Unfortunately, the second question cannot be resolved, as there appear to be few studies which have clearly described within-species metabolic rates during both relaxed wakefulness and sleep. Toutain and Webster (1975) report that, during sleep, $\mathrm{O}_{2}$ consumption in the cow drops by about $10 \%$ from relaxed waking levels and that in the sheep this drop is about $13 \%$. With man, the two main studies (Brebbia \& Altshuler, 1965; Webb \& Hiestand, 1975) find only about a 5\%-10\% overall drop of MR from relaxed wakefulness to average levels during sleep. These small savings of $\mathrm{O}_{2}$ consumption might suggest that sleep, for man at least, might offer other benefits apart from energy conservation. 
Although mammalian advancement has not only brought an increase in body size and a comparable increase in brain size, the additional allometric growth of the cortex brought a relatively large increase in brain size over body size. Thus, the question of whether or not relaxed, but behaviorally alert, wakefulness developed because the food requirement per kilogram of tissue decreases with increasing body size, and therefore, generally speaking, larger mammals might spend less time in pursuit of food, or whether such relaxed wakefulness is a function of cortical development cannot be resolved. It has been argued by Kleitman (1963) that "advanced"' wakefulness is essentially a cortical function, and that wakefulness without such goal-oriented purposes as food seeking, sexual activity, and infant rearing is not to be found in the less advanced mammal. Relaxed and contemplative wakefulness might therefore be associated with cortical advancement.

It would seem that any hypothesis that the prime function of sleep is to conserve energy and to maintain immobility should take into account that this proposal may not apply equally to all mammals. Although this may be the main function of sleep for the smaller and less cortically advanced mammals, the evolution of the cortex and increase in body size of the more advanced mammals indicates that this latter group can maintain immobility without sleeping and that they have less energy conservation to gain through sleeping. Hence, as indicated by, for example, Zepelin and Rechtschaffen (1974), the larger mammals have less TST. But, as will now be seen, it may be the quality of this sleep, particularly of non-REM sleep, rather than any reduction in quantity which may be the salient feature.

Although sleep onset and maintenance structures have been shown by Moruzzi $(1966,1972)$ and Jouvet et al. (1961) to be mostly located in the midbrain and brainstem, Moruzzi's (1966) major review of sleep neurophysiology has proposed that there is no specific requirement by the midbrain and brainstem areas for long periods of rest and recovery; that is, sleep is not required here. These areas, he states, need no additional recovery time apart from the normal refractory period, unlike the cortex, which would appear to need extra restitution for the recovery of plastic (macromolecular) processes involved in learning, etc. Thus, for mammals with simpler brains and relatively small amounts of cortex, there is apparently little need for the brain itself to sleep.

Newborn rabbits and rats, which are normally very immature at birth, show much REM sleep, whereas the newborn guinea pig is more mature and shows less REM (Jouvet-Mounier et al., 1970). Astic (1973) has further qualified these latter findings by showing that REM sleep appears to be the first recognizable sleep stage to develop in the fetal guinea pig, declining with in utero development. These two latter studies suggest that there may be a negative correlation between brain maturity and the amount of REM sleep. The fact that "non-REM" sleep increases proportionally with age may well be associated with the later development of those parts of the brain manifesting non-REM sleep, namely the cortex. So, while REM sleep may be essentially a function of the hindbrain and its earlier development, non-REM sleep may be a manifestation of the development of the intact cortex, with non-REM sleep phylogenetically and ontogenetically culminating in man and higher primates with the EEG subtleties both of $\mathrm{K}$ complexes (Metcalf, Mondale, \& Butler, 1971) and of delta activity (Balzamo, Bradley, \& Rhodes, 1972). Even the fairly arbitrary subdivisions of non-REM sleep into four sleep stages (Rechtschaffen \& Kales, Note 2) indicates clear qualitative distinctions within human sleep.

Finally, if sleep-cycle length can be considered to be related to the quality and organization of sleep, then it is interesting to note from the calculations by Zepelin and Rechtschaffen (1974) that a major determinant of sleep-cycle length would seem to be brain size rather than any other of the constitutional variables assessed.

\section{CONCLUSIONS}

To summarize the main points proposed here, the early mammals, being fairly small (Colbert, 1969), could conserve significant amounts of energy through being immobile, and to these animals sleep may have been primarily an enforced immobilizer for the conservation of energy. REM sleep appears to be one of the earliest sleep stages to evolve. However, it has been suggested that REM sleep may be oriented towards energy conservation, and, at least in mammals with less advanced cortices, may not be essential to the brain per se. This phylogenetic viewpoint may be reflected in the ontogeny of more advanced mammals.

With the evolution of the cortex, sleep may have become more oriented to the brain, and concomitantly or otherwise, sleep may have provided a reduced degree of energy conservation because of the larger body size. The apparently more recent development of sleep within non-REM sleep may be a reflection of "cortical sleep," but the evolution of the cortex may also have provided additional functions for REM sleep.

It might be hypothesized that, if cortical development were to be held constant statistically, then small mammals would have more REM sleep, either as a percentage of TST or in absolute time, than would large mammals. However, such a hypothesis would be confounded by three major variables: (1) safety of the sleeping organism; (2) if REM sleep is associated with energy conservation, then a mammal having less 
need to conserve energy, either because of an ambient environmental temperature or through an efficient insulation against heat loss, might be expected to have less REM sleep than a comparable mammal living under conditions of unwanted body heat loss; and (3) possible changes in the functions of REM and non-REM sleep with phylogeny, which may not be reflected in quantitative changes of these sleep states.

These caveats might make any investigation of any energy conservation hypothesis for REM difficult. Nevertheless, there are conditions, (a) within species and (b) within groups of mammals of the same order and of similar states of cortical development, which might provide for greater amounts of REM sleep.

A within-species comparison can be accomplished by taking, preferably, a less cortically advanced and smaller mammal and encouraging it to conserve energy by either reducing its food intake or placing it in a cooler, but not cold, environment. These conditions would have to be imposed gradually, otherwise an alarm reaction, coupled with the fragility of REM sleep, would result in reduced REM sleep and more awakenings. However, such conditions prevail naturally prior to hibernation. Although no such investigation appears to have been performed, it is interesting to note that Van Twyver (1969), in a comparison of several rodent species, found that nonhibernating hibernators had higher amounts of REM sleep, expressed as percentages of TST, than did nonhibernators. All species had similar amounts of daily TST.

Although a within-order comparison is possible with present data, these data come from a variety of measurement conditions, ranging from animals constrained by cages and recording leads, under environmental temperatures more suitable for the experimenter than for the subject, to telemetered animals living under near natural conditions. These differences in conditions are reviewed by Zepelin and Rechtschaffen (1974). However, from Zepelin and Rechtschaffen's tables, several examples can be taken:

(1) The three examples of the Marsupalia have similar levels of cortical development and sleep safety. However, the North American opossum (1.70 kg body weight, $4.9 \mathrm{~h}$ of daily REM sleep, REM sleep occupying $27 \%$ of the TST) and the water opossum $(0.37 \mathrm{~kg}, 6.6 \mathrm{~h}, 34 \%)$ live in colder environments, with the larger animal having less REM sleep. The third example, the phalanger $(1.62 \mathrm{~kg}, 1.8 \mathrm{~h}, 13 \%)$ is larger and comes from a warmer environment, factors which, according to an energy conservation hypothesis for REM sleep, would lead to less REM sleep.

(2) While the data from the Insectivora comes from animals of similar cortical development, there are differences in environmental temperature and sleep safety, as well as with body size. The European hedgehog $(0.78 \mathrm{~kg}, 3.9 \mathrm{~h}, 28 \%)$ is both larger and lives in a cooler environment than does the desert hedgehog $(0.55 \mathrm{~kg}, 2.7 \mathrm{~h}, 26 \%)$, and, although they have similar sleep safety factors, the differences in REM sleep, particularly of the daily amounts, may be associated more with an energy conservation role for REM sleep. Tenrec $(2.00 \mathrm{~kg}, 2.3 \mathrm{~h}, 15 \%)$ comes from an environmental temperature more similar to that of the desert hedgehog, but has less REM sleepa factor perhaps due to its larger body size and an energy conservation role for REM sleep. The Eastern American mole $(0.04 \mathrm{~kg}, 2.1 \mathrm{~h}, 25 \%)$ comes from an environment similar to that of the star-nosed mole $(0.06 \mathrm{~kg}, 2.2 \mathrm{~h}, 27 \%)$, but has a slightly lower body weight, similar amounts of daily REM sleep, but a little more relative REM sleep.

(3) The data from the Chiroptera (bats) are limited, and as these animals have an unusual thermoregulatory response to cold, further analysis of these data will not be attempted.

(4) The Rodentia data cover a variety of animals. Taking a group of rodents from similar sleep safety and environmental temperature conditions and ranking them in body size, thus: mountain beaver $(1.35 \mathrm{~kg}$, $2.4 \mathrm{~h}, 17 \%)$, rat $(0.28 \mathrm{~kg}, 2.5 \mathrm{~h}, 19 \%)$, hamster $(0.12 \mathrm{~kg}, 3.3 \mathrm{~h}, 23 \%)$, and ground squirrel $(0.10 \mathrm{~kg}$, $3.4 \mathrm{~h}, 25 \%$ ), there would seem to be an inverse relationship between body size and REM sleep. However, the mouse $(0.02 \mathrm{~kg}, 1.2 \mathrm{~h}, 9.5 \%)$ does not follow this trend. But the guinea pig $(1.04 \mathrm{~kg}, 0.8 \mathrm{~h}, 10 \%)$ and the chinchilla $(0.42 \mathrm{~kg}, 1.5 \mathrm{~h}, 12 \%)$, from similar sleep safety and temperature (warm) environments, do follow the trend.

(5) Finally, although the more cortically primitive primates, for example the tree shrew $(0.10 \mathrm{~kg}, 2.6 \mathrm{~h}$, $17 \%)$ and the galago $(0.20 \mathrm{~kg}, 1.2 \mathrm{~h}, 11 \%)$, of similar environments, do appear to follow the trend, it would seem that this relationship might become positive with the cortically advanced species. Hence, going from the rhesus monkey $(6.8 \mathrm{~kg}, 1.2 \mathrm{~h}, 13 \%)$ and the chimpanzee $(52 \mathrm{~kg}, 1.4 \mathrm{~h}, 15 \%)$ to man $(62 \mathrm{~kg}, 1.9 \mathrm{~h}$, $24 \%$ ), there are increasing amounts of REM sleep. Whether or not this may be because of differences both in environmental temperatures and in heat insulation or perhaps because of the development of new roles for REM sleep remains to be determined.

\section{REFERENCE NOTES}

1. World Health Organisation. Energy and protein requirements. Technical Report No. 522, 1973.

2. Rechtschaffen, A., \& Kales, A. (Eds.) A manual of standardised terminology, techniques and scoring system for sleep stages of human subjects. U.S. National Institutes of Health Publication No. 204. 1968. 


\section{REFERENCES}

Allison. T.. \& Cicchetri, D. V. Sleep in mammals: Ecological and constitutional correlates. Science, 1976, 194, 732-734.

Anders. T. F.. Emde, R.. \& Parmelee, A. (Eds.) A manual of standardised terminology. techniques and criteria for the scoring of stages of sleep and wakefulness in new'born infants. Los Angeles: Brain Information Service. 1971.

Astic. L. Ontogenèse des états de vigilance chez le foetus de cobaye. Electroencephalography and Clinical Neurophysiology. 1973. 22, 54-64.

BAKER. M. A. Influence of the carotid rete on brain temperature in cats exposed to hot environments. Journal of Physiology. 1972. 220. $711-728$.

BaKer. M. A.. \& HaYward. J. N. Autonomic basis for the rise in brain temperature during paradoxical sleep. Science. 1967. 157. 1586-1588.

BAKER, M. A.. \& HAYWARD, J. N. The intluence of the nasal mucosa and the carotid rete upon hypothalamic temperature in sheep. Journal of Physiology, 1968, 198. 561-579.

Balzamo, E., Bradley, R. J., \& Rhodes, J. M. Sleep ontogeny in the chimpanzee: From two months to forty-one months. Electroencephalography and Clinical Neurophysiology, 1972. 33. 47-60.

BERGER, R. J. Bioenergetic functions of sleep and activity rhythms and their possible relevance to aging. Federation Proceedings, 1975, 34. 97-102.

Brebia, D. R.. \& Altshuler, K. Z. Oxygen consumption rate and electroencephalographic stages of sleep. Science. $1965,150,1621-1623$.

Colbert. E. H. Evolution of the vertebrates. New Y.ork: Wiley, 1969.

Ditrrichova. J. Development of sleep in infancy. In R. J. Robinson (Ed.). Brain and early behaviour. London: Academic Press. 1969. Pp. 193-204.

Ellingson. S. J. Ontogenesis of sleep in the human. In L. C. Lairy \& P. Salzarulo (Eds.). Experimental study of sleep. Amsterdam: Exerpta Medica, 1975. Pp. 129-149.

Foster. K. G. Development of sweat gland function. In D. F. Roberts \& A. M. Thomson (Eds.), The biology of human fetal growth. London: Taylor and Francis, 1976. Pp. 211-216.

Fox, R. H., \& Edholm, O. G. Nervous control of the cutaneous circulation. British Medical Bulletin, 1963, 19.110-114.

Garma. L.. \& Verley. R. Ontogenèse des états de veille et de sommeil chez pes mammifères. Revue Neuropsychiatrie Infante, 1969. 17, 487-504.

Glotzbach. S. F.. \& Heller. H. C. Central nervous regulation of body temperature during sleep. Science, 1976, 194, 537-539.

Gramsbergen. A., Schwartze, P., \& Pretchl, H. F. R. The post-natal development of behavioural states in the rat. Developmental Psychobiology, 1970, 3, 267-280.

HAYWARD. J. M.. \& BAKER, M. A. A comparative study of the role of the cerebral arterial blood in the regulation of brain temperature in tive mammals. Brain Research, 1969, 16. 417-440.

Hartmann, E. The functions of sleep. New Haven: Yale University Press, 1973.

Henane. R.. Buguet, A., Roussel, B., \& Bittel, J. Variations in evaporation and body temperatures during sleep in man. Journal of Applied Physiology, 1977, 42, 50-55.

Hensel, H. Neural processes in thermoregulation. Physiological Revien's, 1973, 53, 948-1017.

Jacobson, A.. Kales, A., Lehmann, D., \& Hoedemaker, F. S. Muscle tonus in human subjects during sleep. Experimental Neurology, 1964, 10, 418-424.

Jouvet-Mounier. D.. Astic, L., \& LACote, D. Ontogenesis of the states of sleep in the rat. cat and guinea pig during the first post-natal month. Developmental Psychobiology, 1970, 2. 216-239.
Jouvet, M.. Pellin, B., \& Mounier, D. Etude polygraphique des différentes phases du sommeil au cours des troubles de conscience chroniques (comas prolongés). Review' of Neurology, 1961, 105, 181-186.

Kleitman. M. Sleep and wakefulness. Chicago: University Press, 1963.

Meddis, R. On the functions of sleep. Animal Behaviour, 1975, 23. 676-691.

Metcalf, D. R., Mondale, J., \& Butler, F. K. Ontogenesis of spontaneous K-complexes. Psychophysiology. 1971, 8, 340-347.

Moruzzi. G. The functional significance of sleep with particular regard to the brain mechanisms underlying consciousness. In J. C. Eccles (Ed.). Brain and conscious experience. Berlin: Springer Verlag, 1966. Pp. 345-388.

Moruzzi. G. The sleep-waking cycle. Review's of Physiology. 1972, 64, 1-165.

Parmeggiani, P. L., Rabini, C., \& Cattalani, M. Sleep phases at low environmental temperature. Archives of Science and Biology'. 1969, 53, 277-290.

Parmeggiani. P. L.. \& SAbbatini. L. Electromyographic aspects of postural. respiratory and thermoregulatory mechanisms in sleeping cats. Electroencephalography and Clinical Neurophysiology. 1972, 33, 1-13.

Parmeggiani, P. L.. Zamboni. G.. Cianci, T., \& Calasso, M. Absence of thermoregulatory vasomotor responses during fast wave sleep in cats. Electroencephalography and Clinical Neurophy'siology, 1977, 42, 372-380.

Reis, D. J.. Moorhead, D., \& Wooten, G. F. Differential regulation of blood flow to red and white muscle in sleep and defensive behaviour. American Journal of Physiology. 1969, 217, 541-546.

Romer, A. S. The vertebrate body. Philadelphia: Saunders, 1962.

SChmidt-Nielson, K. How animals work. Cambridge: University Press. 1972.

Shapiro. C. M.. Moore, A. T.. Mitchell. D., \& Yodaiken, M. L. How well does man thermoregulate during sleep? Experientia, 1974, 30, 1279-1281.

SMITH, C. A. The physiology of the newborn infant. Springfield, Ill: Thomas, 1959.

SNYDER. F. Towards an evolutionary theory of dreaming. American Journal of Psychiatry, 1966, 123, 121-136.

TAYLOR, C. R. The vascularity and possible thermoregulatory function of the horns in goats. Physiology and Zoology. 1966, 39, 127-139.

Taylor, C. R., Schmidt-Nielsen, K., \& RaAb, J. L. Scaling of the energetic cost of running to body size in mammals. American Journal of Physiology, 1970, 219, 1104-1107.

Toutain, P.-L., \& Ruckebusch, Y. Sécrétions nasolabiales au cours du sommeil paradoxal chez les bovins. C. R. Academie de Science (Paris), 1972, 274, 2519-2522.

Toutain, P.-L., \& Webster, A. J. Equilibre énérgetique au cours du sommeil chez les ruminants. $C$. R. Academie des Sciences (Paris), 1975, 281, 1605-1608.

TuCKER, V. A. Energetic cost of locomotion in animals. Comparative Biochemistry and Physiology, 1970, 34, 841-846.

Van TwYver, H. Sleep patterns in five rodent species. Physiology and Behavior, 1969, 4, 901-905.

WebB, P., \& Hiestand, M. Sleep metabolism and age. Journal of Applied Physiology, 1975. 38, 257-262.

Zepelin, H., \& Rechtschaffen, A. Mammalian sleep, longevity and energy metabolism. Brain and Behavioural Evolution, 1974, 10, 425-470.

(Received for publication March 29. 1977; accepted July 5, 1977.) 